\title{
The Research on Construction of Power System Telecommunication Network Operation and Maintenance Hierarchy
}

\author{
Ziyan Zhao, Shulin Zhang,Xin Jin \\ Information \& Communication Dispatching and Control Center, State Grid Information \&Communication Branch, China \\ ziyan-zhao@sgcc.com.cn, shulinzhang@sgcc.com.cn,jinxin@sgec.com.cn
}

\begin{abstract}
Power system communication network operation \& maintenance is most important for power system stability. With the development of power system communication network and the merging of information and communication, the requirement of power system communication management is higher and higher. And the rules of power system communication network is much more complex than before. So it is very urgent for power system communication department to establish the power system operation and maintenance hierarchy to meet the changing situation. In this paper, based on the analysis the current work for power system communication operation and maintenance, a power system communication operation and maintenance with "one data platform, two management principle lines, three operation and maintenance modules" is carried out. The conclusion and scheme put forward in this paper is very helpful for the construction of operation and maintenance hierarchy of power system communication departments.
\end{abstract}

Keywords — power system communication ,maintenance, dispatching, operation, overhaul

\section{INTRODUCTION}

Power system communication network is the basic information transmission network for power system production and management. And now, the three main communication method in telecommunication network in china are fibre, microwave and PLC. With the modernization of power grid and power enterprise, the basic support of telecommunication is more and more obvious[1].

Recently with the rapid increasing of scale of network and the number of services that telecommunication network carries, the importance of telecommunication network operation and maintenance is more and more obvious. In order to improve the support to the construction of smart grid and modern power grid corporation, the telecommunication departments had been adjusted and optimized, and the modern telecommunication network operation and maintenance hierarchy had been just established[2]. With the optimization and deepen of modern power grid development, the hierarchy of telecommunication network operation and maintenance is required to adjust to satisfy the current situation. The main purpose of the adjustment is to establish a Hierarchy which make the modules of telecommunication network operation and maintenance more fluent which includes dispatching, operation and maintenance, and the three models can support each other[3][4].

\section{OVERVIEW OF TELECOMMUNICATION NETWORK OPERATION AND MAINTENANCE}

Commonly, the main work for power system telecommunication network operation and maintenance can be classified as : power system telecommunication business management ,operation and maintenance management. And according to the life cycle of power system telecommunication network, all the works make up the whole closed cycle of power system telecommunication network management that includes: network planning, network construction, network maintenance and the other related auxiliary works. As far as the power system telecommunication network operation and maintenance work itself is concerned, it plays a very important role in the telecommunication network management. For example, the hidden troubles which discovered during network operation and maintenance can guide the telecommunication network planning, construction and optimization directly. And also the telecommunication network operation and maintenance has the most and direct impact on the power grid and power system corporations. 


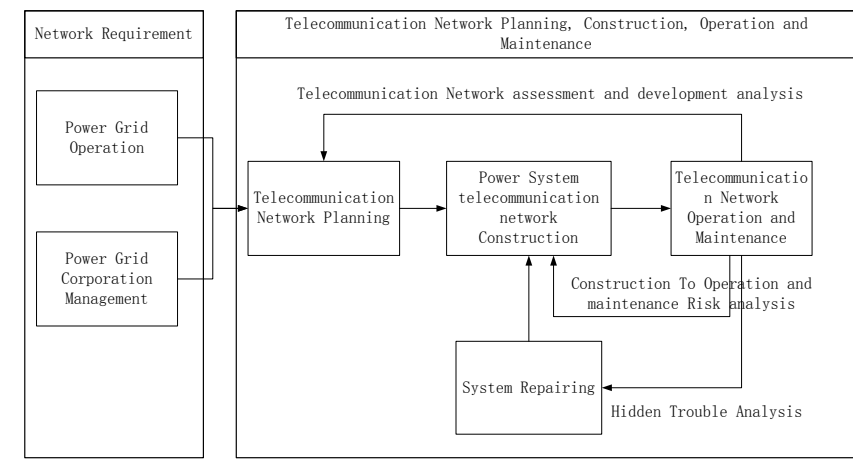

Figure 1. The relationship of power system telecommunication network management works

Power system telecommunication network operation and maintenance is the basic work of all the works among the network management for power system. The main tasks for power system telecommunication network operation and maintenance are as follows:

- guarantee all the services of power system operation and power grid corporation management;

- power system telecommunication network elements operation state monitoring;

- all the channels that carried power system operation and corporation management business services operation state monitoring;

- direct the regional maintenance teams to deal with power system telecommunication network alarm and failure;

- according to the telecommunication network operation data analysis, optimize the telecommunication network.

Like electric power system, the power system telecommunication network is not only a physical network but a logic network. The physical network includes: power system telecommunication station, fibre Network, optical fibre transmission devices, etc . And the logic networks which are carried and running on the physical telecommunication network includes: data communication network, power system dispatching voice switching network, administrative voice switching network, synchronization network, communication signalling network, etc .

III.CHALlenges fOR POWER SySTEM TELECOMMUNICATION NETWORK OPERATION AND MAINTENANCE
In recent years, with the rapid development of power system telecommunication network, the scale of network has already been several times bigger than before. And the power system operation requires much more safe and reliable communication service supports. So, the power system telecommunication network operation and maintenance is now facing the following challenges:

Firstly, the service scale of power grid operation and power grid corporation management had increased a lot; How to arrange those power grid services and guarantee the safe and reliable service communication transmission support is much more difficult. Besides with the merging of information and communication ,the basic operation and maintenance rule of power system telecommunication network becomes more and more complex which the two aspects of information and telecommunication should be considered together. As far as the traditional power system telecommunication network operation and maintenance hierarchy is concerned ,the traditional operation and maintenance hierarchy ,mechanism and methods have certain restrictions. The original hierarchy, ideas and methods should be adjusted and optimized.

Secondly, the power system telecommunication network operation and maintenance hierarchy can be classified as three models which are dispatching, operation and maintenance. However the interface among three modules are not very clear which makes it very difficult for the three models of telecommunication operation and maintenance to develop harmoniously. And now for the power system telecommunication department place particular emphasis on real time power grid operation services, especially when alarm and faults occurs. And the most important modules are telecommunication dispatching and maintenance. The function of operation is dispersed into dispatching and maintenance. When considering the current situation, The main reason why the boundary of the three models above are not very clear is that there are different understanding with the contents of power system telecommunication dispatching, operation and maintenance. And now the ideas of power system telecommunication network management still remains on the network 
device and communication channel maintenance. However when facing the more and more complicated telecommunication network and power grid service requirements, power system telecommunication network operation function module can't give enough support to the network dispatching and maintenance which restricts the improvement of telecommunication network management.

Thirdly, the rapid development of smart power grid and modernization development of power grid corporation requires not only the safe and stable operation support of power grid service ,but also the improvement of efficiency of power system telecommunication department which need to optimize the three function modules of telecommunication network management. That is to say the telecommunication function model should give enough support to the telecommunication dispatching and maintenance models. And the telecommunication operation model should play a more important role in the telecommunication network management.

So as mentioned above, it is very urgent and necessary for the power system telecommunication network management department study how to reconstruct the hierarchy of power system telecommunication network management, define the interface and function of each models which should support each other and develop harmoniously.

\section{IV.THE OPERATION AND MAINTENANCE HIERARCHY OF MODERN POWER SYSTEM TELECOMMUNICATION NETWORK MANAGEMENT}

\section{A. The Framework Operation and Maintenance Hierarchy}

The purposes to reconstruct the hierarchy of power system telecommunication network operation and maintenance management are: For one thing, it is to satisfy the current requirement of smart power grid and modern power grid corporation development; For another, it is to form the new ideas of telecommunication network management for power system which will make the current hierarchy more optimal and efficiency; Lastly, when building the new hierarchy, all the inner interfaces and work flows will be reconstructed based on the new ideas that will make the current operation and maintenance work more scientific and efficiency.

The modern telecommunication network operation and maintenance hierarchy for power system includes three parts:

- One Telecommunication Network Operation and Maintenance Database Platform, which includes: telecommunication network real time operation data, network topology data, network resource data, network safety and risk data;

- Two Principle Lines for Telecommunication Network Operation and Maintenance Management, which includes: the real-time management line based on telecommunication network dispatching and the non real-time management line based on telecommunication network operation management ;

- Three Telecommunication Network Function Models, which includes: telecommunication network dispatching, operation and maintenance models.

\section{B. Network Operation and Maintenance Database Platform}

Database is the basis of telecommunication network operation and maintenance management for power system. It will be impossible for the power system communication department to judge the communication system alarm and fault ,to direct the maintenance team to deal with the communication system problems. As far as the communication system for power system there are two kinds of data, one is the real time data which is usually collected in the communication network management system, and the other is the non real time data which includes: the network topology data ,communication network resource data and communication network risk points data. These non real time data usually are generated during communication network planning ,construction and the routine checking-ups.

\section{Two Principle Lines for Network Operation and Maintenance Management}

For power system communication network management there are two principle lines in network operation and maintenance management. 
The real time network management principle line focus on the network dispatching and deal with the real time alarm and fault. While the non real time network management principle line focus on the network operation and network analysis.

When the scale of communication network is small, it will be easy for the power system communication department to deal with the problems of communication devices and channels. However when the communication network becomes larger and larger, the communication network operation and maintenance becomes much more complex. And the focus on power system communication network has been changing slowly. The union network operation and maintenance which covers the whole network and runs through the physical layer to the business service systems. So it needs to change the tradition network operation and maintenance idea that fits for the small communication network, monitor and control the whole communication network operation state. Then we could apply the safety and risk control strategy on the whole network.

As mentioned above, it is more and more clear that the power system communication network operation and maintenance work has been given the new content. According to the character of the network operation and maintenance work, two principle power system communication network principle management lines could be defined as :real time principle line and non real time principle line.

\section{Three communication network operation and maintenance models}

According to the power system operation and maintenance content and the relationship between each work the power system communication network operation and maintenance hierarchy could be classified as three modules: dispatching model, operation model and maintenance model. The three models above supplement each other and support the safe and stable operation of power system together. Based on the hierarchy above, the power system communication network operation and maintenance matrix could be summarized as Figure 2:

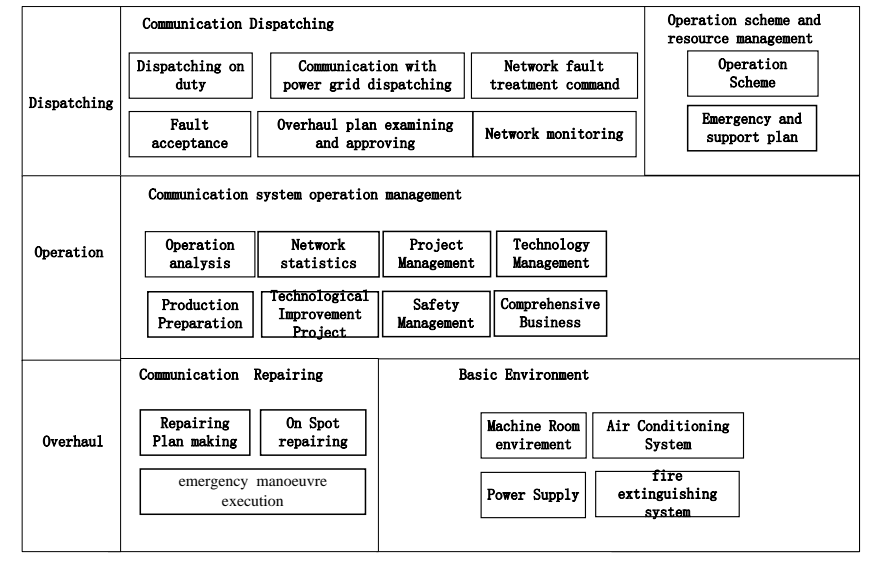

Figure 2. Power System Communication Network Operation and Maintenance Work Matrix

In the power system network operation and maintenance work matrix above:

- The main function of the Dispatching Model is real time monitor and dispatching command, which includes the following works : communication on duty, communication with the power system dispatching department, Communication network fault or power system service failure acceptance, operation scheme and overhaul plan examining and approving, Communication network operation schemes and network resource management, Emergency and Support plan making, etc.

- The main function of the Operation Model is the power system communication network operation analysis and comprehensive management, mainly includes: network operation analysis, network and operation statistics, communication network project management , communication network technology management, power system communication network production preparation , technical improvement projects ,safety management and comprehensive business management.

- The main function of the Overhaul model is the power system communication network spot operation and repairing, mainly includes: communication overhaul plan making and execution, network fault or power grid service failure on spot repairing, emergency manoeuvre execution, basic environment and air-conditioning system inspection . 


\section{Hierarchy OpERATION MEChaNism}

The final goal for the reconstruction of power system communication network operation and maintenance hierarchy is to make all models within the hierarchy to operate fluently and efficiently that can satisfy the requirement of power system communication network development and management level improvement.

Based on the idea: "one database platform, two principle management lines, three operation and maintenance models ", The operation and maintenance hierarchy meets the situation of more rapid development of power system communication network and more higher requirement of centralized communication network management.

The reconstructed power system communication network operation and maintenance hierarchy includes:

1)One Database Platform: collects the data of power system real time dispatching service, power system communication network structure, power system communication network resources, power system communication safe and risk information, etc . Based on the database platform, not only real time communication network fault and power grid service failure could be supported, but also the non real time and long-term power system communication network plan, construction and optimization could be supported.

2)Two Principle Management Lines includes: the real time dispatching line and non real time communication system operation management line, which make the key points of power system communication network operation and maintenance more clear. All the communication and maintenance works could be connected and applied according to the two principle management lines. The real time dispatching line focus on the network operation state monitoring and network fault or power grid failure dispatching command, while the non real time communication system operation management line focus on the long-term development of power system communication network which develop the basic work on communication network assessment, optimization and planning. For the non real time principle line deal with the power system communication network from the whole network, so it is the key point that keeps the power system communication network safe ,reliable and stable.

3)The three Operation and Maintenance Models include: power system communication network dispatching, operation and overhaul models. In the new hierarchy, the function of dispatching, operation and overhaul are defined separately. Each model has its own function and interface. With this separation, the communication network operation model is configured independently which has much different compared with the traditional hierarchy. With the separated operation model both the real time alarm and fault treatment and on spot standard repairing could be supported with the analysis of network real time state, network resources and network safe and risk evaluation. And this hierarchy satisfied the large scale communication network management.

The relationship of power system communication network dispatching, operation and overhaul models and their operation mechanism is shown as Figure 3: 


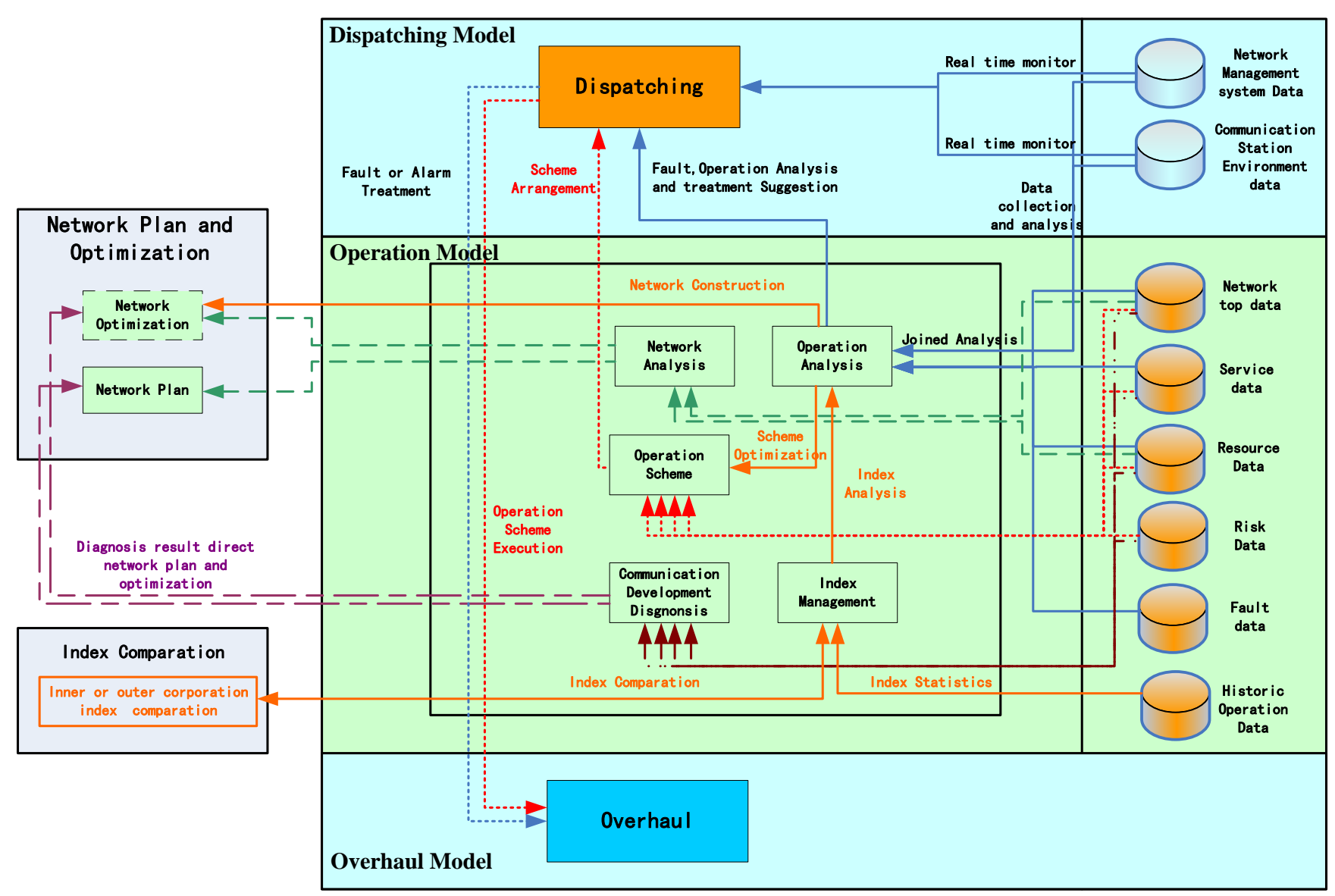

Figure 3. Relationship and Mechanism of operation and maintenance hierarchy

The hierarchy mentioned above shows the relationship of each models, and the hierarchy has the characteristics as followings :

1) centralized power system communication network dispatching;

2) strong and deep analysis ability of power system communication network operation;

\section{3) standard and simple on sport repairing.}

With this hierarchy, the analysis ability of on spot repairing will be overcame by the increasing support of centralized power system communication network operation analysis support. And the hierarchy meets the larger scale power system communication network centralized management requirement.

\section{Conclusion}

The reconstruction of power system communication network operation and maintenance hierarchy is so important for the communication department of power system that it will affect the communication network operation and maintenance quality and efficiency directly, and affect the safe and stable operation of power system indirectly. With the higher requirement of centralized management of power system communication network, the network operation and maintenance hierarchy needs more intelligence and analysis ability. The hierarchy carried out in this paper meets the requirements above. However the principle rules and characters for power system communication network operation and maintenance will be changing with communication technology progress and management improvement. Further work on support application system for power system operation and maintenance with new hierarchy should be developed for actual work.

\section{REFERENCES}

[1] ziyan zhao, jianming liu. A New Reliability Evaluation Method for Electric Telecommunication Network Based on Service Risk Degree Balancing [J]. Power System Technology, 2011, 35 (10) : 209212. 
[2] mingying gu, yan zhang, minghai wei, The Research On Power System Operation and Maintenance Model of ShanXi Power Grid Corportation $[\mathrm{J}]$. Power System Communication , 2012, 33 (235) : 70-72.

[3] yun liang, jiming yao, jianbo liu, Power System Information\&Communication Operation and Maintenance Hierarchy Discussion [J]. Value Project, 2012, 31 (36) : 43-44.

[4] ru xu, The Application of Operation and Maintenance Management in Power System Communication Network [J] . NingXia Electric Power, 2012, 6: 25-26.

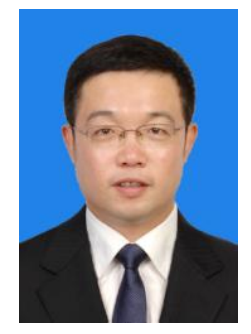

Ziyan Zhao(1975.03--),PH.D, major in electric power system automation, and got the PH.D in 2011 at CEPRI(China Electric Power Institute). And now work in State Grid information\& Communication Branch, Beijing, China.

email: ziyan-zhao@sgcc.com.cn 